Ana Maria Brasileiro, bacharel em direito, mestre em administração pública (Universidade da Califórnia do Sul), PhD em ciências políticas (Universidade de Essex), consultora do Fundo das Nações Unidas para a Infância - UNICEF.

\title{
Serviços básicos para áreas urbanas
}

\section{A cidade e os serviços urbanos}

A origem e o desenvolvimento das cidades perdem-se na história dos tempos. A maioria dos autores vê o surgimento das cidades como decorrência da capacidade do campo de produzir um excedente suscetivel de sustentar uma classe não diretamente produtiva, constituída pelos sacerdotes, administradores e militares. Há porém os que, como Jane Jacobs, acreditam que a vida urbana é tão inerente ao ser humano que precedeu mesmo o desenvolvimento da agricultura. O homem tomou posse do campo partindo-se de aglomerações urbanas, de cidades. Qualquer que seja a posição adotada, é certo que, em momento algum da história da humanidade, tantos viveram tão próximos uns dos outros. ${ }^{1}$

A concentração, que não é apenas demográfica mas também e principalmente econômica, se faz acompanhar de novas formas de organização e convivio social. Muito do que antes podia ser, resolvido por mecanismos privados mais ou menos isolados passou a depender, e cada vez mais, de uma ação coletiva organizada. Proliferam as instituições públicas, semipúblicas e privadas. Surgem para 'resolver' os problemas básicos da humanidade, criando-lhe muitas vezes outros, inclusive sérios. Por meio delas, por exemplo, reforçam-se com freqüência processos de discriminação e distanciamento social.

O Estado, crescentemente intervencionista, passa a ocupar-se de praticamente todos os assuntos de relevância para a vida em sociedade.

Paralelamente, manifesta-se na coletividade a expectativa de ver praticamente todos os seus pro- blemas atendidos por essa categoria 'externa', ou melhor, pela sua manifestação básica, o 'governo' (a população o identifica como 'eles' e, portanto, o contrapõe a 'nós', o povol.

Percebido por cada um como principal responsável pelo seu bem-estar, ou, o que é mais comum, pelo seu 'mal-estar', recebe o governo as demandas, as queixas, as raivas, as pressões e as esperanças da sociedade.

É na grande e média cidade que a sensação de dependência (e a dependência ela própria) em relação ao governo parece estar mais presente. A solução de problemas básicos - como a necessidade de água potável, alimentação adequada, moradia, transporte, cuidados com a saúde e outros manifesta-se ai diretamente relacionada com a ação do Estado e de suas instituições. Na visão da maior parte da sociedade, mesmo problemas não tão facilmente identificados com agências governamentais prestadoras de serviços, como o custo de vida e o desemprego, dependem, para sua solução, da atuação eficiente e eficaz do Estado.

A correlação entre problemas e a ação ou omissão do Estado parece ser mais forte e como tal percebida nas áreas urbanas. $\mathrm{O}$ sentimento de fatalismo la identificação das causas de cada situação com fatores mágicos como o destino, a vontade de Deus, e a decorrente aceitação pacífica da situação) tende ai a ser menor. Isso favorece, no contexto urbano, a organização da ação coletiva de tipo reivindicatório em sindicatos, associações e movimentos sociais. 
Embora os problemas mencionados sejam básicos para a sociedade em geral, a sua manifestação nas cidades assume, para aqueles destinados a resolvê-las, sem dúvida características que justificam, em relação a muito deles, o título de 'problemas urbanos' e o de 'serviços urbanos'. Um serviço de transporte coletivo aparece apenas em situações de certa densidade demográfica, quando o número de deslocamentos é suficiente para justificar a manutenção de uma frota de ônibus, de uma rede ferroviária suburbana ou de sistema fluvial ou marítimo...

As necessidades de água e o sistema de esgotos em áreas de grande densidade populacional podem apenas ser adequadamente satisfeitas quando concebidas como parte de um sistema mais amplo, de rede, consideradas as interconexões com outros sistemas. Da mesma forma, o serviço de limpeza urbana e o de iluminação pública. O abastecimento alimentar adquire, na cidade, conotações também distintas. No campo é ainda possível - embora cada vez menos, o que explica em parte o êxodo - uma certa dose de auto-suficiência. Hortas, pequenas plantações e a criação de animais, às vezes transacionados em sistema de escambo (trocas em espécie), respondem em muitas áreas pelas necessidades de alimentação de parte da população rural. Nas áreas urbanas isso não é possivel, ou o é em escala muito reduzida. A economia tende também a ser muito mais monetarizada. $\mathrm{O}$ abastecimento se faz através de uma rede complexa, com grande número de intermediários, envolvendo grande número de instituições.

Mesmo os serviços sociais, como a educação, a saúde e a assistência social, tendem a adquirir, em contexto muito urbanos, certa especificidade. Mudanças em instituições como a família, geradas por exemplo pela expansão do trabalho feminino fora do lar, com reflexos sobre o cuidado das crianças e a própria reprodução da força de trabalho, acabam criando novas demandas por serviços públicos (creches, pré-escolar, atenção ao menor abandonado, suplementação alimentar etc.). Condições precárias de higiene e saneamento associadas à situação de alta densidade demográfica (como as existentes em favelas, cortiços e algumas áreas da periferia urbana) exigem também um novo enfoque para os programas de saúde pública.

O Estado 'organiza-se' para a prestação dos serviços - urbanos ou não - descentralizando e setorializando sua ação. Diversos níveis de governo (União, estados e municípios em sistemas federais como o nossol, com competências e recursos distintos, e dentro de cada um deles diversos órgãos setoriais, desconcentrando-se regionalmente e constituindo o conjunto da administração direta e indi- reta, desincumbem-se, com maior ou menor eficiência, da forma mais ou menos 'racional', com maior ou menor dose de conflito institucional, de tarefas previamente identificadas. Respondem, assim, pelo menos em tese às demandas criadas pelo desenvolvimento da sociedade. Expande-se a burocracia governamental, recriando e reproduzindo processos impregnados na sociedade, como o clientelismo, o patrimonialismo e a discriminação sócio-ecônomica.

Obedece, nessa expansão, a fatores que escapam em grande medida ao controle da própria sociedade, como os ditados pela inserção do país na ordem econômica internacional.

A ação governamental processa-se necessariamente fragmentada em diversos órgãos e níveis. A complexidade da vida moderna exige, cada vez mais, a divisão das tarefas governamentais, o que propicia a criação de novas agências e a expansão de atingas. Essa mesma complexidade, refletindose em contextos cada vez mais urbanos e interdependentes, demanda esforcos crescentes de planejamento, articulação e integração institucional, dificeis de obter, mas necessários na tentativa de solucionar problemas e melhorar as condicões de vida da população. Os problemas, por sua vez, revelamse sempre de forma globalizante, una, indivisivel, reforçando a necessidade de ação governamental conjunta e multidimensional. O que uma agência faz tem sempre a ver com as atribuições de várias outras e vice-versa.

\section{A pobreza urbana}

A eliminação da situação de pobreza que atinge um imenso contingente da população mundial representa, sem dúvida, um grande desafio para a humanidade e, em especial, para os países ditos do Terceiro Mundo onde ela se aglomera.

A população pobre rural vem, em grande parte, transferindo-se para as cidades por meio de fluxos migratórios contínuos. A pobreza que chega e a que aí é gerada vão competir, em desigualdade de condições, pelo acesso aos recursos escassos emprego, renda, moradia, alimentação, prestígio, saúde etc. - existentes e disponíveis e pelos que serão ainda criados. Sem grandes alternativas, alojamse, como podem, em areas desprezadas (pelo menos de início) pelos setores de mais alta renda, ocupando morros, alagados e vazios suburbanos. O espaço segrega-se, refletindo a estrutura das dificuldades sociais. A cidade se decompõe em áreas de alta e média renda e áreas de baixa renda facilmente identificáveis, cada uma delas exibindo características, serviços e amenidades distintas.

A condição de privação cumulativa faz com que os segmentos mais pobres da sociedade se ve- 
jam excluídos simultaneamente de benefícios sociais, culturais, econômicos e políticos já alcançados pelos demais. A falta de renda e recursos materiais é acompanhada, na imensa maioria dos casos, por péssimas condições de moradia, alimentação deficiente, saúde precária, baixo nível de escolaridade, pouco prestígio social... As áreas que Ihes servem de moradia são, em geral, mal situadas e desprovidas de serviços públicos.

A ocupação muitas vezes ilegal e irregular da terra tem se revelado, na prática, uma das justificativas mais comumente ultilizadas para a exclusão de favelas e loteamentos clandestinos da programação governamental. Ao lado da ausência dos serviços, os moradores se vêem ainda confrontados pela ameaça (às vezes efetivada) de remoção.

Sendo a pobreza determinada, isto e, causada por outros fatores - como as relações de poder existentes - é claro que a eliminação da pobreza não pode ser conseguida partindo-se dela própria, isoladamente. ${ }^{2}$ A mudança social em direção a sociedades mais igualitárias pressupõe transformacões estruturais profundas, envolvendo não apenas o pais mas a própria ordem internacional.

Diversas ideologias disputam o privilégio de indicar o caminho para essas mudanças. Nenhuma pode oferecer a garantia de que a história vai efetivamente caminhar segundo o modelo prescrito. ${ }^{3} \mathrm{~A}$ realidade é sempre mais dinâmica e contraditória do que é possível prever-se.

No cerne da disputa ideológica coloca-se o Estado e o papel que este desempenha na eliminação - perpetuação da pobreza. 4 Vê-se ele confrontado, de um lado, pela necessidade de garantir o 'desenvolvimento', concebido em função da posição que o país ocupa no concerto das nações e de processos internos ao próprio país. Em países como o nosso, essa tendência tem sido traduzida, na prática, por um tipo de desenvolvimento assimétrico, excludente, concentrador.

Por outro lado, o Estado, em função de outros processos que se contrapõem ou reforçam os primeiros, se vê chamado a responder a demandas oriundas de todos os segmentos da sociedade. A busca da legitimidade e as próprias exigências do sistema econômico fazem-no receptivo e 'responsivo' a parte dessas démandas.

A chamada 'crise social', caracterizada pelo número crescente de pessoas que se vêem impossibilitadas de enfrentar, de forma adequada, as suas necessidades básicas - e aqui poderíamos talvez até incluir algumas necessidades geradas por aspirações de natureza consumista, dificeis de resistir - representa estímulo significativo para a ação do Estado voltada para os segmentos de mais baixa renda na sociedade.

\section{A estratégia dos serviços básicos 5}

A estratégia dos serviços básicos, que conta com o respaldo de organismos internacionais ligados à ONU, tem por objetivo promover, a curto e médio prazos, a extensão de serviços considerados imprescindíveis ao bem-estar da população a áreas até então deles privadas. Partindo de diagnósticos que apontam números espantosos para a situação de pobreza no mundo (700 milhões de pobres nas áreas rurais e 200 milhões nas áreas urbanas) 6 , esses organismos passaram a promover, junto aos governos dos países onde atuam, o desenvolvimento de metodologia destinada a sanar essas deficiências a curto e médio prazos.

A estratégia inicialmente concebida para áreas rurais enfatiza a simplicidade tecnolóyica e aúministrativa, o baixo custo na prestação dos serviços e o envolvimento da própria comunidade a ser atendida em todas as fases do programa (no estabelecimento de prioridades, na implementação, na avaliação e na reformulação de projetos).?

Dado o caráter de extrema interdependência dos problemas e dos serviços destinados a suprir as necessidades básicas, propõe ela um enfoque multissetorial integrado. Os serviços devem ser oferecidos de forma integrada em cada comunidade, evitando-se a desarticulação e a oferta isolada.

Como a responsabilidade pela prestação desses serviços é compartilhada por diversas agências (ministérios, secretarias estaduais e municipais e órgãos da administração indireta, no nosso caso) e dada a inviabilidade de buscar-se uma integração de caráter abstrato, em nível dos órgãos, a efetivação dessa integração deve-se dar na área, objeto da intervenção. Busca-se a convergência de ações das diferentes agências na comunidade a ser atendida.

Entre os serviços a serem incluídos em programações baseadas na estratégia, estão: cuidados com a criança e a gestante, produção e consumo de alimentos de maior teor nutritivo, reabilitação alimentar, sistemas confiáveis de água, esgoto e coleta de lixo, pré-escolar e educação básica, cuidados com a saúde (medicina preventiva e curativa), melkoria na habitação e no ambiente imediato e programas de geração de renda.

Questões de natureza prática sugerem, muitas vezes, que os serviços sejam instalados gradativamente, de tal forma que, passado certo tempo, se tenha conseguido a presença e integração de todos eles na mesma comunidade.

A meta prioritária nessa estratégia é a do atendimento do mais necessitado, do mais carente. Nem sempre é possível, contudo, atingi-la de início ou apenas a ela. Essa população tende a ser menos 
acessivel e organizada em termos de ação coletiva, o que acarreta dificuldades extras de natureza metodológica e administrativa.

Os objetivos específicos de uma política social de tal natureza podem assim ser enumerados: 1? ajudar o pobre urbano a gerar a renda de que necessita. Isso pode ser tentado pela capacitação profissional, apoio por meio de crédito e outros mecanismos às atividades que já desenvolve e serviços de apoio (como creches, no caso do trabalho feminino); $\left.2^{\circ} .^{\circ}\right)$ garantir-Ihe atenção adequada no que se refere ao seu desenvolvimento físico e mental e ao seu bemestar (cuidados na área de saúde, principalmente medidas preventivas, da educação e da assistência social); $3^{\circ}$ ) introduzir melhorias no seu ambiente fisico em cooperação com as iniciativas da própria comunidade; $4^{\circ}$ ) encorajar o uso de tecnologia apropriada, inclusive pela introdução de tecnologias simples no âmbito da moradia, que redundem em redução do esforço doméstico.

O modelo é deixado propositadamente aberto, como alternativas, para garantir certa flexibilidade e possibilidade de adaptação aos casos concretos.

A prestação de serviços pode ser concebida em diferentes níveis, desde o nv́el da comunidade. Nesse nível - primário de atendimento - a utilização de pessoal local leigo, característica da estratégia, tem-se revelado um dos principais fatores responsáveis pela aceleração da oferta desses serviços e pelo baixo custo observado. ${ }^{8}$ Esse pessoal, quase sempre residente na comunidade onde presta seus serviços, trabalha de forma voluntária ou remunerada, em tempo parcial ou integral. ${ }^{9}$ Após receber treinamento incumbe-se de diversas tarefas ligadas à prestação dos serviços, desempenhando ainda uma função motivadora e educativa junto à população beneficada.

O segundo nivel - 'nivel de encaminhamento' - representa o ponto mais próximo dentro de um sistema de serviços básicos ao qual o trabalhador de nível primário pode encaminhar os membros de sua comunidade que precisem de tratamento ou conselho e onde ele próprio, junto com outros trabalhadores primários, recebe suas instruções, busca apoio e dá conta de suas atribuições.

O terceiro nível - 'nível de supervisão/coordenação' - deve ser da responsabilidade dos governos locais. O planejamento local identifica as áreas carentes a serem incluídas no programa e desenvolve as propostas de ação para a área, reunindo os diversos componentes a serem ativados, a metodologia e os recursos necessários e disponiveis.

A participação comunitária se faz presente desde a fase de seleção das áreas até a da identificação de necessidades, elaboração, implementação e avaliação de projetos. Há técnicas já desenvolvidas (como o autodiagnóstico) que facilitam esse processo.

Com referência aos serviços de responsabilidade de outros níveis governamentais há que se desenvolver mecanismos de articulação que permitam a participação dos órgãos diretamente relevantes nas decisões e que garantam a convergência de ações. ${ }^{10}$

A 'nível nacional', quarto e último nível de um programa de serviços básicos voltado para as áreas urbanas carentes, compete a coordenação e articulação das ações que, desempenhadas por diversas agências e departamentos governamentais, afetam mais diretamente os aspectos relacionados com o desenvolvimento social nas áreas urbanas. Cabe-lhe também induzir, orientar, articular e apoiar, técnica e administrativamente, a atuação dos niveis infranacionais de governo e da iniciativa privada relevante.

Ao lado da introdução de tecnologias apropriadas, a estratégia preconiza também o estabelecimento de procedimentos legais e administrativos simples e expeditos, de fácil compreensão pela população participante e adequadas à sua situação sócio-econômica. Relatório do Banco Mundial sobre o Brasil conclui que o maior obstáculo à ampliação da cobertura dos serviços de habitação, água e esgoto não está tanto na suposta escassez de recursos orçamentários que pudessem ser destinados às áreas mais carentes, mas sim nas limitações legais e operativas das agências encarregadas daqueles serviços. A manter-se inalteradas as normas vigentes, não há como estender os serviços às famílias de baixa renda impossibilitadas de pagar as prestações ou as tarifas exigidas. 11

Entre as objeções que foram levantadas contra a estratégia, tem recebido maior destaque a afirmação de que a mesma não conduz a mudanças estruturais. Atuaria, em conseqüência, como um fator a mais na manutenção do status quo, das desigualdades sociais. Programas dessa natureza estariam voltados para a 'administração da pobreza', sem qualquer teor redistributivista. Ao se ocuparem das populações de baixa renda, estariam considerando essa população como desajustada, sem atentar para o fato de que esse 'desajuste' é ocasionado por razões estruturais ao próprio sistema.

Outra crítica comum é a que se refere ao trabalho voluntário em sistema de mutirões, que a metodologia muitas vezes preconiza.

"Não é o mutirão, transformado em sobretrabalho do operariado, que deve ser utilizado para cobrir as deficiências de serviços e equipamentos comunitários existentes principalmente nas áreas habitadas por populações de baixa renda. Ele vem ape- 
nas reforçar as desigualdades sociais, disfarçar as omissões do Estado e retardar a mudança social."12

Se, por um lado, parece ser verdade que a tônica da estratégia está principalmente voltada para a melhoria das condições de vida da população mais necessitada, facilitando-lhe o acesso a bens e serviços que respondem às suas necessidades básicas, sem preocupação explícita com mudanças estruturais, por outro, é menos evidente que programas dessa natureza funcionem com obstáculo a essas mudanças. O contrário parece mais plausivel. A simples presença do Estado, levando serviços a áreas antes praticamente desassistidas, traz em si um potencial de mudança nada desprezível. Um dos seus efeitos é estimular o processo de reivindicação popular, muitas vezes paralisado em função da sensação de abandono e impotência das populações de áreas esquecidas. Por meio desse processo, é comum, também, o estabelecimento de redes de comunicação informais entre técnico e morador que facilitam o acesso desse último aos canais burocráticos relevantes. Melhorias efetivas nas condições de vida da população parecem também estar correlacionadas com maior capacidade de organização comunitária e de mobilização social. Uma população muito sofrida, mal alimentada, pouco saudável e quase sem recurso não tem a mínima condição de mobilizar-se para tentar influir em políticas governamentais.

A utilização do trabalho voluntário em projetos tipo mutirão, voltados para obras e serviços nas comunidades de baixa renda, pode realmente ser considerada injusta do ponto de vista da sociedade como um todo. Os segmentos de alta e média renda têm acesso a esses serviços, em quantidade e qualidade adequadas, sem que para isso precisem mobilizar-se em ação coletiva e empregar seu tempo disponível (para o lazer e outras atividades) em tarefas que, em princípio, são da competência do Estado. $\mathrm{O}$ argumento comumente empregado como justificativa para o fato - a maior contribuição fiscal desses segmentos - não procede, já que se sabe que, em sociedades muito assimétricas, os sistemas tributários tendem a ser regressivos, penalizando proporcionalmente mais as classes de menor poder aquisitivo. Dada a situação real e a correlação de forças existentes em sociedades como a nossa, em que a omissão do Estado em relação às áreas habitadas por essas populações é freqüente, os mutirões, reunindo esforços da comunidade e recursos do governo, acabam representando um avanço em relação à situação anterior. Conscientes desse fato, crescem as demandas das comunidades menos privilegiadas para apoio desse tipo.

Não é tampouco desprezível o efeito aglutinador e auto-educativo que tais projetos acarretam nas comunidades. A organização comunitária favorece a reflexão sobre a situação de pobreza e a ação coletiva do tipo reivindicatório.

Considerada como elemento intrínseco à estratégia dos serviços básicos, a participação efetiva da comunidade a ser beneficiada, inclusive na tomada de decisão em pontos fundamentais dos projetos, representa sem dúvida um fator importante le não tão facilmente manipulável como às vezes se afirma) no processo de mudança social.

$\mathrm{O}$ argumento mais poderoso a ser usado a favor da estratégia reside, contudo, nos ganhos efetivos já obtidos em países que resolveram aplicá-la seriamente. Na América Central, no Peru, na İndia, na China a estratégia conseguiu expandir significativamente e em prazo relativamente curto o alcance dos serviços, com resultados favoráveis (e às vezes assombrosos) nos indices de mortalidade infantil, morbidade, escolaridade e bem-estar geral das populações de baixa renda.

\section{Notas}

1. Em função de diversos processos sócio-econômicos, já bastante estudados, aceleram-se no último século os fluxos migratórios em direção, principalmente, aos médios e grandes centros. Associados ao crescimento vegetativo, que embora acusando certo decréscimo é ainda significativo, dão origem à chamada 'expansão urbana'. Na América Latina espera-se para a virada do século uma população urbana equivalente a $75 \%$ da total.

2. No caso do Brasil os dados são eloqüentes. Embora do ponto de vista do acesso a serviços básicos, como água e esgoto, registrem-se ganhos em termos das unidades habitacionais atendidas, a distribuição da renda concentrou-se ainda mais, nas últimas décadas, quando o poder de barganha desses segmentos e da sociedade como um todo - se restringiu. A comparação entre os censos de 1970 e 1980 indica que os $50 \%$ da população urbana nos niveis mais baixos de renda, que em 1970 detinham $16,01 \%$ do total da renda, passam a deter apenas $14,90 \%$ em 1980. Os $10 \%$ de renda mais elevada exibem, em contrapartida, um aumento de $44,39 \%$ para $46 \%$ na década. Em 1980, a remuneração do trabalhador urbano com rendimento de um a dois salários mínimos é 4\% menor do que em 1970. O que ganha mais de 20 salários mínimos, contudo, vê sua renda real aumentada em 9\% em relação a 1970.

3. "A História como um todo e, em particular, a história das revoluções é sempre mais rica de conteúdo, mais variada, mais multiforme, viva e cheia de engenho do que chegam a imaginar os grupos em que há maior refinamento e as mais conscientes vanguardas das mais avançadas classes." V.II. Lenine, Left. Wing Communism - an infantile disorder. Londres, 1967. p.401. (Selected works, v.3)

4. Esse tema não será aqui aprofundado. Há uma vasta literatura sobre ele, refletindo a multiplicidade de pontos de vista.

5. Sobre a estratégia ver: UNICEF, Urban Basic Services: Reaching children and women of the urban poor, Report by Executive Director, 1982. Serviços básicos para a infância em países em desenvolvimento (Relatório do diretor executivo do UNICEF à Junta Executiva, Sessão de 1976, UNICEF Doc. E/ICEF/L.1342. Reimpressão, 1979. The management of the delivery of urban basic services, UNICEF April/May 1981 (mimeo.), Social planning with the poor - new government strategies in assignment children, $57 / 58$, 1982.

6. Estimativa do Banco Mundial. 
7. No Brasil ela vem sendo desenvolvida com o apoio do UNICEF, já com bons resultados, nos municípios do Rio de Janeiro e Recife. Estuda-se, no momento, a possibilidade de aplicar a metodologia a nível nacional, via CNDU. Ver relato da experiência no Rio em: BRASILEIRO, Ana Maria et al. Extending municipal services by building on local alternatives - a project in the favelas of Rio de Janeiro, in Assignmet Children, op. cit. p.67-100.

8. Ver UNICEF, Serviços básicos para a infância em países em desenvolvimento. Doc. E/ICEF/L.2342, 1979 (reimpressão).

9. Há vantagens e desvantagens em cada um dos sistemas de envolvimento dos membros da comunidade: trabalho voluntário ou remunerado. A opcão será feita segundo as características do projeto específico e da área a ser atingida.
10. Essa é talvez a maior dificuldade enfrentada por um Programa de Serviços Básicos para áreas carentes. Muitas vezes mecanismos informais de articulação poderão funcionar satisfatoriamente, contornando dificuldades de formalização de acordos e convênios ou da criação de conselhos ou comitês entre órgãos de niveis governamentais distintos.

11. KNIGHT, Peter T. \& MORAN, Ricardo. Brazil - poverty and basic needs series, Washington, Banco Mundial, 1981, n.p.

12. AMMAN, Safira Bezerra. Consideracões críticas sobre o conceito de participação. São Paulo, 2(5): 152, mar. 1981. Ver também: Ideologia do desenvolvimento de comunidade no Brasil. São Paulo, 5: ed. 1980. 